\title{
Patients', Staff, and Providers' Factual Knowledge About Hospital Chaplains and Association with Desire for Chaplain Services
}

J Gen Intern Med 37(3):697-9

DOI: $10.1007 / \mathrm{s} 11606-020-06388-8$

() Society of General Internal Medicine 2021

\section{INTRODUCTION}

Chaplains support patients as a part of interdisciplinary health care teams. Chaplain involvement is associated with higher patient-reported quality of life and satisfaction with care. ${ }^{1,2}$ Although health systems employ staff chaplains as a standard component of patient care, evidence suggests that patients and staff have limited understanding of chaplain's role as they engage and mediate spiritual, emotional, and existential concerns of health care. ${ }^{3,4}$ An interdisciplinary partnership within the Duke University Health System is currently piloting the extension of chaplain services into the outpatient primary care setting. As part of this project, we conducted a needs assessment, surveying patients, accompanying caregivers, staff, and providers regarding their knowledge of chaplains' training and scope of practice. We hypothesized that deficits in knowledge may decrease utilization of chaplains in appropriate circumstances.

\section{METHODS}

We collected this electronic survey from a convenience sample of patients and accompanying caregivers at the Duke Outpatient Clinic adult internal medicine teaching practice; we additionally queried all providers and staff using an emailed survey. The principal focus was respondents' factual understanding of chaplains' roles, expertise, and training. Additional questions asked about patients' demographics and desire for chaplains' assistance in a variety of hypothetical situations. Surveys were collected using REDCap electronic data capture tools hosted at Duke. ${ }^{5}$ We assessed for associations between independent variables and respondents' factual knowledge by conducting multiple logistic regression using STATA. ${ }^{6}$ The Duke University Institutional Review Board determined our study to be exempt from review.

Received November 1, 2020

Accepted December 2, 2020

Published online January 22, 2021

\section{RESULTS}

In total, 78 patients and 10 accompanying caregivers completed surveys out of 113 persons approached (response rate of $78 \%$ ). Of 116,74 members of the clinic team completed surveys (response rate of 64\%). Table 1 describes participants' factual knowledge about chaplains. Clinic team members of a variety of disciplines were significantly more likely to answer questions correctly than patients/caregivers, answering a mean of 7.9 out 10 questions correctly compared to patients' 5.5/10. These differences persisted after adjustment for demographics. In questions regarding chaplains' relationship to institutional religion, only a minority of both groups of respondents correctly identified that chaplains do not begin their work simply after receiving approval from their church, and that chaplains are trained to respond to the needs of patients from any religious background. Regarding chaplains' application of religious practices and theology, only a minority of patients correctly identified that chaplains' work was not to save people or teach religious practices and principles. A large majority of respondents correctly reported chaplains' general roles in providing support to patients at the end-of-life and broadly assisting patients and staff. Overall, patients' factual knowledge was not associated with desire for chaplain services $(p=$ 0.60 ); however, as demonstrated in Figure 1, patients who correctly identified chaplains' role were more likely to definitely desire chaplain services than those who answered incorrectly ( $53 \%$ vs. $25 \%, p=.02$ ).

\section{DISCUSSION}

Our study demonstrates the existence of knowledge gaps about chaplaincy among patients and staff in this outpatient clinic. Patients and providers may falsely think that chaplains in an academic medical setting are working as paid representatives of the chaplains' religious denomination instead of hospital staff who can support patients from any background. Second, the medical team may misperceive that chaplains are trained only to respond to religious patients or more specifically patients from their own tradition. Finally, staff and patients are generally unaware of chaplains' broad-based standardized training requirements. Improved knowledge of chaplaincy services could have multiple benefits for medical teams and patients. Team members who understand and appreciate 
Table 1 Percentage of Clinical Team Members and Patients/Caregivers with Correct Responses to Factual Questions About Chaplains' Roles with Unadjusted and Adjusted Odds Ratios and $t$ Test

\begin{tabular}{|c|c|c|c|}
\hline Factual questions (grouped by themes) & $\begin{array}{l}\text { Physicians and advance practice } \\
\text { provider and non-physician staff } \\
\text { Percent correct }\end{array}$ & $\begin{array}{l}\text { Patients and } \\
\text { caregivers } \\
\text { Percent correct }\end{array}$ & $p$ value \\
\hline \multicolumn{4}{|l|}{ Chaplain's relationship institutional religion } \\
\hline $\begin{array}{l}\text { 1. A chaplain's job includes inviting people to their religion. } \\
\text { (answer: false) }\end{array}$ & $\begin{array}{l}89 \% \\
\text { Ref }\end{array}$ & \multirow{2}{*}{$\begin{array}{l}57 \% \\
\text { OR } 0.15 \\
\text { AOR } 0.25 \\
35 \% \\
\text { OR } 0.16 \\
\text { AOR } 0.25\end{array}$} & $\begin{array}{l}p<0.001^{\dagger \dagger} \\
p=0.010^{\dagger}\end{array}$ \\
\hline $\begin{array}{l}\text { 2. Chaplains represent the church that employs them. (answer: } \\
\text { false) }\end{array}$ & $\begin{array}{l}77 \% \\
\text { Ref }\end{array}$ & & $\begin{array}{l}\mathrm{p}<0.001^{\dagger \dagger} \\
p<0.001^{\dagger \dagger}\end{array}$ \\
\hline $\begin{array}{l}\text { 3. A professional chaplain can begin his/her work after getting the } \\
\text { approval of his/her church (answer: false) }\end{array}$ & $\begin{array}{l}40 \% \\
\text { Ref }\end{array}$ & \multirow{2}{*}{$\begin{array}{l}35 \% \\
\text { OR } 0.80 \\
\text { AOR } 0.71 \\
35 \% \\
\text { OR } 0.72 \\
\text { AOR } 0.73\end{array}$} & $\begin{array}{l}p=0.487 \\
p=0.487\end{array}$ \\
\hline $\begin{array}{l}\text { 4. Chaplains do not have the training and resources to respond to } \\
\text { the needs of every religion. (answer: false) }\end{array}$ & $\begin{array}{l}43 \% \\
\text { Ref }\end{array}$ & & $\begin{array}{l}p=0.325 \\
p=0.498\end{array}$ \\
\hline $\begin{array}{l}\text { Chaplain's application of religious practices and theology } \\
5 \text {. Chaplains' main job is to give people their last rites before } \\
\text { death. (answer: false) }\end{array}$ & $\begin{array}{l}89 \% \\
\text { Ref }\end{array}$ & \multirow{3}{*}{$\begin{array}{l}65 \% \\
\text { OR } 0.22 \\
\text { AOR } 0.56 \\
44 \% \\
\text { OR } 0.17 \\
\text { AOR } 0.21 \\
48 \% \\
\text { OR } 0.21 \\
\text { AOR } 0.26\end{array}$} & $\begin{array}{l}p=0.001^{\dagger \dagger} \\
p=0.365\end{array}$ \\
\hline 6. A chaplain's job includes saving people. (answer: false) & $\begin{array}{l}82 \% \\
\text { Ref }\end{array}$ & & $\begin{array}{l}p<0.001^{\dagger \dagger} \\
p=0.003\end{array}$ \\
\hline $\begin{array}{l}\text { 7. Chaplains preach religious principles and practices to patients. } \\
\text { (answer: false) }\end{array}$ & $\begin{array}{l}81 \% \\
\text { Ref }\end{array}$ & & $\begin{array}{l}p<0.001^{\dagger \dagger} \\
p=0.017^{\dagger}\end{array}$ \\
\hline $\begin{array}{l}\text { Chaplains' roles } \\
8 \text {. Chaplains only see patients who are dying or may die soon. } \\
\text { (answer: false) }\end{array}$ & $\begin{array}{l}99.7 \% \\
\text { Ref }\end{array}$ & \multirow{4}{*}{$\begin{array}{l}82 \% \\
\text { OR } 0.06 \\
\text { AOR } 0.07 \\
75 \% \\
\text { OR } 0.17 \\
\text { AOR } 0.11 \\
75 \% \\
\text { OR } 0.13 \\
\text { AOR } 0.05 \\
\text { Mean } 5.5 / 10 \\
\text { STD 2.9 }\end{array}$} & $\begin{array}{l}p=0.008^{\dagger \dagger} \\
p=0.033^{\dagger}\end{array}$ \\
\hline $\begin{array}{l}\text { 9. Beyond helping patients, chaplains can help health care team } \\
\text { members with difficulties. (answer: true) }\end{array}$ & $\begin{array}{l}95 \% \\
\text { Ref }\end{array}$ & & $\begin{array}{l}p=0.002^{\dagger \dagger} \\
p=0.006^{\dagger \dagger}\end{array}$ \\
\hline $\begin{array}{l}\text { 10. A health care team member may call a chaplain for any patient } \\
\text { who seems to be struggling. (answer: true) }\end{array}$ & $96 \%$ & & $\begin{array}{l}p=0.001^{\dagger \dagger} \\
p=0.003^{\dagger \dagger}\end{array}$ \\
\hline Total correct responses & $\begin{array}{l}\text { Mean } 7.9 / 10 \\
\text { STD } 1.8\end{array}$ & & $p<0.001^{\dagger \dagger}$ \\
\hline
\end{tabular}

OR odds ratio, AOR adjusted odds ratio, STD standard deviation. Adjusted by gender, age under 35, black race, protestant religion, education less than college degree, and self-reported religiosity

$p<0.05$

${ }^{71} p<0.01$

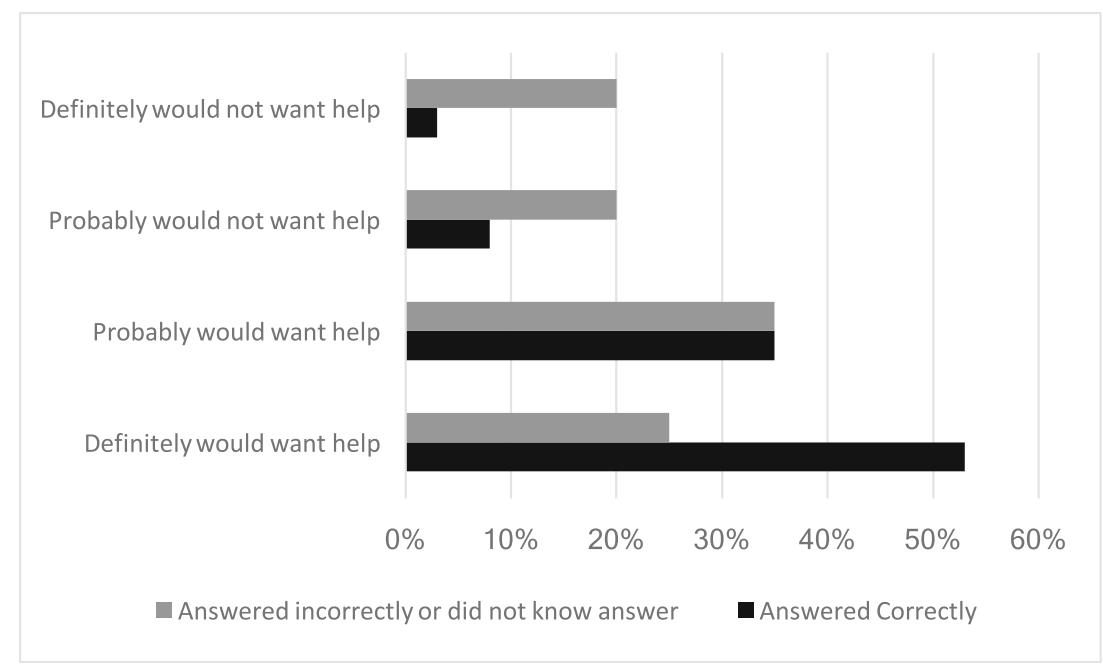

Figure 1 Patients' reported desire for meeting with a chaplain as a "listening ear," compared by correct understanding of chaplain's role in the following question: "True or False: beyond helping patients, chaplains can help health care team members with difficulties." 
chaplains' expertise will likely be more inclined to make referrals. Patients who understand the chaplain's role may be more likely to request or accept their services for a variety of situations. Our findings support a positive association between understanding chaplains' roles and desire for chaplain services.

Our survey was conducted at a single site and may have limitations to its generalizability. However, this is the first known study to specifically assess factual knowledge about chaplaincy among patients and medical team. These survey questions could be a model for clinics in primary care or other specialties in seeking to measure barriers and facilitators to the inclusion of chaplaincy. Future steps include studying educational or outreach efforts that seek to improve understanding of chaplain services.

Alissa Stavig, $M D^{1,2}$

Lynn A. Bowlby, MD, FACP ${ }^{3}$

John P. Oliver, D.Min., BCC, ACPECE ${ }^{4}$

Katherine K. Henderson, $M R P^{4}$

Jan Dillard, MSW, LCSW

Elissa Nickolopoulos, MSW, LCSW-A ${ }^{5}$

Patrick Hemming, MD, $\mathrm{MPH}^{1}$

${ }^{1}$ Department of Medicine, Duke University Medical Center,

Durham, NC, USA

${ }^{2}$ Department of Psychiatry and Behavioral Sciences, Duke University Medical Center,

Durham, NC, USA

${ }^{3}$ Division of General Internal Medicine, Department of Medicine, Duke University Medical Center,

Durham, NC, USA

${ }^{4}$ Department of Chaplain Services and Education, Duke University Hospital,

Durham, NC, USA
${ }^{5}$ Duke Outpatient Clinic (DOC), Department of Case Management and Clinical Social Work, Duke University Medical Center,

Durham, NC, USA

Corresponding Author: Alissa Stavig, MD; Department of Psychiatry and Behavioral Sciences, Duke University Medical Center, Durham, NC, USA (e-mail: Alissa.stavig@duke.edu).

Funding This work was supported by a grant from Duke AHEAD (Academy for Health Professions Education and Academic Development).

\section{REFERENCES}

1. Astrow AB, Wexler A, Texeira K, He MK, Sulmasy DP. Is failure to meet spiritual needs associated with cancer patients' perceptions of quality of care and their satisfaction with care? J Clin Oncol. 2007;25(36):57535757.

2. Kruizinga $\mathbf{R}$, Hartog ID, Jacobs $\mathbf{M}$ et al. The effect of spiritual interventions addressing existential themes using a narrative approach on quality of life of cancer patients: a systematic review and meta-analysis. Psychooncology. 2016;5(3): 253-265.

3. Cunningham CJL, Panda M, Lambert J, Daniel G, DeMars K. Perceptions of Chaplains' Value and Impact Within Hospital Care Teams. J Relig Health. 2017;56(4): 1231-1247.

4. Damen A, Labuschagne D, Fosler L, O'Mahony S, Levine S, Fitchett G. What Do Chaplains Do: The Views of Palliative Care Physicians, Nurses, and Social Workers. Am J Hosp Palliat Care. 2019;36(5):396-401.

5. Harris PA, Taylor $\mathbf{R}$, Thielke $\mathbf{R}$, Payne $\mathbf{J}$, Gonzalez $\mathbf{N}$, Conde JG Research electronic data capture (REDCap) - A metadata-driven methodology and workflow process for providing translational research informatics support. J Biomed Inform. 2009;42(2):377-81.

6. StataCorp. Stata Statistical Software: Release 16. College Station, TX: StataCorp LLC; 2019.

Publisher's Note: Springer Nature remains neutral with regard to jurisdictional claims in published maps and institutional affiliations. 